\title{
Use of Real-Time Quantitative PCR to Validate the Results of cDNA Array and Differential Display PCR Technologies
}

\author{
Mangalathu S. Rajeevan, ${ }^{1}$ Daya G. Ranamukhaarachchi, Suzanne D. Vernon, \\ and Elizabeth R. Unger
}

Division of Viral and Rickettsial Diseases, National Center for Infectious Diseases, Centers for Disease Control and Prevention, U.S. Department of Health and Public Services, Atlanta, Georgia 30333

Real-time reverse transcription polymerase chain reaction (RTPCR) methods that monitor product accumulation were adapted for the validation of differentially expressed genes. We describe a real-time quantitative PCR assay that uses SYBR Green I dye-based detection and product melting curve analysis to validate differentially expressed genes identified by gene expression profiling technologies. Since SYBR Green I dye is a nonspecific intercalating dye, the reaction is made specific by using "hot-start" PCR and empirically determined annealing and signal acquisition temperatures for each gene-specific primer. Relative expression levels were quantified by constructing a standard curve using CDNA dilutions of a highly expressed gene. Using this approach, real-time PCR validated 17 of 21 (71\%) genes identified by DNA arrays, and all but 1 of 13 (91\%) genes identified by differential display PCR (DDPCR). Validation of differentially expressed genes detected by array analysis was related to hybridization intensity. Real-time RT-PCR results suggest that genes identified by DNA arrays with a two to fourfold difference in expression cannot be accepted as true or false without validation. Validation of differentially expressed genes detected by DD-PCR was not affected by band intensities. Regardless of the gene expression profiling technology (microarrays, DDPCR, serial analysis of gene expression and subtraction hybridization), once the sequence of gene of interest is known, the realtime RT-PCR approach is well suited for validation of differential expression since it is quantitative and rapid and requires 1000 -fold less RNA than conventional assays. @ 2001 Elsevier Science (USA)

Key Words: gene expression profiling technologies; validation; real-time polymerase chain reactions; LightCycler.

\footnotetext{
1 To whom correspondence and reprint requests should be addressed. Fax: (404) 639-3540. E-mail: mor4@cdc.gov.
}

DNA arrays (microarrays) and differential displayPCR (DD-PCR) are two of the leading technologies to identify differentially expressed genes and genomewide transcription patterns. The reliability of these techniques to detect transcriptional differences representative of the original samples is affected by several factors. Microarray results are influenced by array production, RNA extraction, probe labeling, hybridization conditions, and imageanalysis (1-4). DD-PCR results are affected by electrophoretic resolution, weak and differential priming, analysis of banding patterns and procedures for band characterization (5).

Because of the inherent limitations in reliability, genes identified as differentially expressed must be validated with another method. N orthern blot hybridization or RNase protection assays are effective but requirea minimum of $5 \mu \mathrm{g}$ of total RNA. Conventional reverse transcription-polymerase chain reaction (RT$P C R$ ) requires much less RNA, but end-point analysis lacks precision for a quantitative determination (6-8). Real-time RT-PCR methods that monitor product accumulation are the current state-of-the-art for gene quantitation $(7,8)$. We adapted this procedure for the validation of differentially expressed genes identified by DNA arrays (9). In this report, we provide a detailed description of the real-time PCR methodology and its integration with DNA array and DD-PCR technologies for validation of differentially expressed genes. 


\section{DESCRIPTION OF METHOD}

Basic Strategy

To achieve the flexibility required to validate the large numbers of genes identified by expression profiling technologies, we chose LightCycler-based real-time PCR with product detection using generic SYBR Green I dye. In addition, rather than constructing an absolute standard curve with serial dilutions of known template for each gene, a relativestandard curve was constructed to permit comparison between samples. The relative standard curve is simply constructed using serial dilutions of cDNA prepared from one sample identified in the gene profiling technique as having a high expression level of the gene to be validated.

Whilestill requiring the design and synthesis of genespecific primers, the expense of the special chemistry required for synthesis of gene-specific fluorogenic internal probes is eliminated. In addition, the specificity of the reaction is monitored by determination of the product melting temperature ( $T_{\mathrm{m}}$ : defined as the temperature at which half of DNA helical structure is lost). Reaction specificity is improved by "hot-start" PCR and by acquiring signal at a temperature $1-2^{\circ} \mathrm{C}$ below the $\mathrm{T}_{\mathrm{m}}$ of specific product, avoiding the nonspecific signal from primer-dimers that usually melt at lower temperatures (10).

\section{Real-Time RT-PCR Conditions}

\section{Reverse Transcription Reaction}

The same source of total RNA used in primary gene expression profiling should beused in validation experiments. The SuperScript First Strand Synthesis System for RT-PCR (I nvitrogen, Carlsbad, CA) was used to synthesize cDNA in a $20-\mu$ l reaction containing $1 \mu \mathrm{g}$ of DNase I-treated total RNA, $20 \mathrm{mM}$ Tris- $\mathrm{HCl}(\mathrm{pH} 8.4)$, $50 \mathrm{mM} \mathrm{KCl}, 2.5 \mathrm{mM} \mathrm{MgCl}_{2}, 10 \mathrm{mM}$ dithiothreitol (DTT), $0.5 \mu \mathrm{g}$ oligo(dT) ${ }_{12-18}, 0.5 \mathrm{mM}$ each of dATP, dGTP, dCTP, and dTTP, and $200 \mathrm{U}$ SuperScript II Reverse Transcriptase. In terms of the order of adding reaction components, RNA and oligo(dT) were mixed first, heated to $70^{\circ} \mathrm{C}$ for $10 \mathrm{~min}$, and placed on ice until addition of the remaining reaction components. The reaction was incubated at $42^{\circ} \mathrm{C}$ for $1 \mathrm{~h}$, and terminated by heat inactivation at $70^{\circ} \mathrm{C}$ for $15 \mathrm{~min}$. The cDNA product was treated with $2 \mathrm{U}$ of RNase $\mathrm{H}$ (Invitrogen) for $20 \mathrm{~min}$ at $37^{\circ} \mathrm{C}$, followed by heat inactivation of the enzyme at $70^{\circ} \mathrm{C}$ for $15 \mathrm{~min}$. An identical reaction without the reversetranscriptase was performed to verify the absence of genomic DNA (no-RT control). The cDNA was stored at $-20^{\circ} \mathrm{C}$ until ready to use. Purification of CDNA prior to real-time PCR was not necessary.

\section{Determination of Real-Time PCR Conditions}

An initial annealing temperature was selected for each primer pair based on their computed $T_{m}$ 's using GENSET OLIGOS, Oligo Version 4, (GENSET Corp., La J olla, CA) or PRIMERSELECT of LASERGENE software (DNASTAR, Inc., Madison, WI). The annealing temperature was increased or decreased from the computed $T_{m}$ 's in steps of $2-3^{\circ} \mathrm{C}$ until the $T_{m}$ 's of the specific product and that of the primer-dimers or nonspecific products were separated by at least $3-5^{\circ} \mathrm{C}$. This allows the signal acquisition to be set $1-2^{\circ} \mathrm{C}$ below the $\mathrm{T}_{\mathrm{m}}$ 's of the specific product, minimizing signal interference from nonspecific products.

\section{Reaction Setup and Cycling Conditions}

All instructions outlined in the LightCycler Manual (Roche Molecular Biochemicals, Indianapolis, IN) were followed for setting up the reactions in glass capillaries. Two microliters of DNA Master SYBR Green I mixture (containing Taq DNA polymerase, dNTP, $\mathrm{MgCl}_{2}$, and SYBR Green I dye; Roche Molecular Biochemicals) was incubated with $0.16 \mu \mathrm{l}$ TaqStart Antibody (Clontech, Palo Alto, CA) for $5 \mathrm{~min}$ at room temperature prior to the addition of primers and cDNA template. I $n$ addition to the Master Mix, each reaction (20 $\mu \mathrm{l})$ contained $2 \mu \mathrm{l}$ of CDNA dilution, $0.4 \mu \mathrm{M}$ each primer, and $4 \mu \mathrm{M} \mathrm{MgCl}_{2}$. Generally 1:200 and 1:2000 dilutions of CDNA were used, but analysis of extremely low-abundancemessage could require less dilute cDNA for detection. Duplicate reactions were prepared for each dilution along with a no-template negative control $\left(\mathrm{H}_{2} \mathrm{O}\right.$ control). No standard curve was used with these optimization assays. The cycling conditions used to determine primer-specific PCR conditions consisted of 1 cycle at $95^{\circ} \mathrm{C}$ with $60-\mathrm{s}$ hold for denaturation and "hot start" followed by 50 three-segment cycles for amplification $\left[95^{\circ} \mathrm{C}\right.$ with 0 -s hold, test annealing temperature with 5-s hold, product el ongation and signal acquisition (single mode) at $72^{\circ} \mathrm{C}$ with 18-s hold] and 1 three-segment cycle of product melting $\left(95^{\circ} \mathrm{C}\right.$ with 0 -s hold, $65^{\circ} \mathrm{C}$ with 10 -s hold, and $95^{\circ} \mathrm{C}$ with 0 -s hold at the step acquisition mode). The temperature transition rate for all segments of the amplification cycles and the melting curve cycle were set at $20^{\circ} \mathrm{C} / \mathrm{s}$ except that it was set at $0.2^{\circ} \mathrm{C} / \mathrm{s}$ for segment 3 of product melting curveanalysis. The annealing temperature that yiel ded the most specific product at reaction endpoint with a $T_{m}$ separated from nonspecific product $\mathrm{T}_{\mathrm{m}}$ by at least $3-5^{\circ} \mathrm{C}$ was selected. The signal acquisition temperature was set to equal specific product $\mathrm{T}_{\mathrm{m}}-1$ or $2^{\circ} \mathrm{C}$. If the annealing temperature did not 
result in a single specific product with $T_{m}$ adequately resolved from nonspecific products, the time of annealing could be adjusted to improve reaction specificity. Otherwise, redesign of primers would be required to achieve the desired specificity.

\section{Validation Experiments}

\section{Experimental Conditions}

After empiric determination of the annealing and acquisition temperatures, reactions for determining the relative gene expression in samples were set up. Sample preparation for PCR in capillary tubes was performed as described above. The relative standard curve was prepared with duplicate serial dilutions (1:200, and $1: 2000$, and $1: 20,000)$ of cDNA from a sample with the highest predicted levels of expression of the gene being investigated. Template concentrations for the relative standard were given arbitrary values of $0.5,0.05$, and 0.005. The samples for comparison were analyzed as unknowns using duplicate 1:200 dilutions of cDNA. Whilea no-template negative control $\left(\mathrm{H}_{2} \mathrm{O}\right.$ control $)$ was run with every gene-specific primer, the no-RT-PCR control was run with only one primer pair that could amplify contaminated genomic DNA. The no-RT-PCR controls were set up in duplicate using primers for glyceraldehyde-3-phosphate dehydrogenase (G3PDH) and 1:200 dilution of no-RT templates of all samples to be compared.

Thermal cycling was initiated with 1 cycle at $95^{\circ} \mathrm{C}$ with 60-s hold for denaturation and "hot start" followed by 50 four-segment cycles for amplification $\left(95^{\circ} \mathrm{C}\right.$ with 0 -s hold, primer-specific annealing temperature with 5 -s hold, product elongation at $72^{\circ} \mathrm{C}$ with 18-s hold, and product-specific signal acquisition temperature with 2-s hold) and one cycle of product melting $\left(95^{\circ} \mathrm{C}\right.$ with 0 -s hold, $65^{\circ} \mathrm{C}$ with 10 -s hold, and $95^{\circ} \mathrm{C}$ with 0 -s hold in the step acquisition mode). The temperature transition rate for the first three segments of the amplification cycles and the first two segments of the melting curve cycle was set at $20^{\circ} \mathrm{C} / \mathrm{s}$. F or segment 4 of the amplification cycles the temperature transition rate was set at $5^{\circ} \mathrm{C} / \mathrm{s}$, and for segment 3 of the melting curve cycle it was set at $0.2^{\circ} \mathrm{C} / \mathrm{s}$.

To be acceptable, at least two of the three relative standard curve dilutions in an assay must yield specific product (based on $\mathrm{T}_{\mathrm{m}}$ ) and the no-template control should have no product or primer-dimer product melting lower than the signal acquisition temperature. If only one of the standard curve dilutions produced detectable product, appropriate adjustments in the dilutions were required to generate the minimum two points for therelativestandard curve. If primer-dimers interfered at the acquisition temperature, conditions of the PCR assay should be adjusted as described above. If no-RT controls show specific products by melting curve analysis, then RNA samples should be treated with DNase I for complete removal of DNA prior to using these samples for validation of other genes.

\section{Calculations}

Each assay set (duplicates of CDNA dilutions of standards and unknown, and the negative control) was re peated and calculations were made using all results from both assay sets. The default (fit point/arithmetic) method of LightCycler Software Version 3 based on kinetic approach $(7,8)$ was used to determine the relative starting copy numbers of target in each reaction. Details of themethod are provided in the LightCycler Manual. Briefly, the noise band or crossing line is set to exclude noninformative background fluorescence data from quantitative analysis. The standard curve is generated based on the values of crossing points (defined as the cycle number at which the noise band intersects thefluorescent curves) and the log value of thestandard concentration. (For the relative standard curves, the concentrations are set arbitrarily as 0.5, 0.05, and 0.005 for dilutions of 1:200, 1:2000, and 1:20,000). The LightCycler program calculates a concentration value for the starting target concentration in each reaction. Concentration values corresponding to the 1:200 cDNA dilution of samples to be compared are used to calculate the relative expression levels and coefficients of variation (CVs). Table 1 presents an example of the concentration values obtained for the gene fibronectin in 1:200 cDNA dilutions of two samples, and calculations of relative expression levels and CVs.

\section{USE OF REAL-TIME PCR FOR VALIDATION OF GENE EXPRESSION}

The RT-PCR approach described above can be readily integrated to validate the results of any primary differential gene expression screening method (cDNA arrays, DD-PCR, serial analysis of gene expression, and subtraction hybridization) once the sequence of the candidate gene is known. This section describes the evaluation and integration of the real-time quantitative PCR protocol for validation of gene expression results from micro- or high-density arrays and DD-PCR methods. Steps in the overall procedure are outlined in Fig. 1. 
Validation of DNA Array Results

Differential expression of genes identified with any array platform (CDNA or oligonucleotide) can be validated with the procedure described above. As an example, we used cDNA based high-density filter arrays (Atlas Human Cancer cDNA Expression Array; Clontech) to identify genes differentially expressed between two subcl ones (20863 and 20861) of W12 cervical epithelial cells harboring human papillomavirus 16 (HPV16) in different physical states (9). Genes for validation were selected on the basis of their absolute hybridization intensity (subclone 20863 as reference) as well as their relative intensity (subclone 20863 to subclone 20861).

\section{Gene-Specific Primers to Validate Array Results}

For the Clontech arrays, the manufacturer provides sequence information for the gene-specific primers used to generate the PCR fragments spotted on the arrays. In this instance, all that was required was the synthesis of the specified primers. If this information is not available, gene-specific primers could be designed (using sequence information deposited in GenBank) for validation of results from array platforms. Primers should be 17-24 bases yielding a transcript-specific product of 150- 650 bp. Products $>650$ bp arenot amplified consistently by the LightCycler. Specificity is improved by avoiding highly conserved regions in members of multigene families.

\section{TABLE 1}

Calculating Relative Expression Level and Coefficients of Variation ${ }^{\mathrm{a}, \mathrm{b}}$

\begin{tabular}{llcc}
\hline & & \multicolumn{2}{c}{$\begin{array}{c}\text { Concentration value at } \\
1: 200 \text { cDNA dilution }\end{array}$} \\
\cline { 3 - 4 } $\begin{array}{c}\text { Gene } \\
\text { (fibronectin) }\end{array}$ & & $\begin{array}{c}\text { Sample 1 } \\
\text { (standard) }\end{array}$ & $\begin{array}{c}\text { Sample 2 } \\
\text { (unknown) }\end{array}$ \\
\hline \multirow{2}{*}{ Assay 1 } & & 0.447 & 0.0285 \\
& & 0.559 & 0.0226 \\
Assay 2 & Mean & 0.503 & 0.0255 \\
& Intraassay CV & $15.7 \%$ & $16.32 \%$ \\
& & 0.556 & 0.0203 \\
& Mean & 0.45 & 0.0298 \\
& Intraassay CV & 0.503 & 0.0250 \\
& Mean of assays & $14.9 \%$ & $26.8 \%$ \\
& Interassay CV & 0.503 & 0.025 \\
& & $15.32 \%$ & $21.57 \%$
\end{tabular}

Relative expression level (sample 1/sample 2) $=0.503 / 0.025=$ 20-fold

a Coefficient of variation (CV) $=$ (standard deviation/mean) $\times 100$.

${ }^{\mathrm{b}}$ Based on concentration values determined by real-time quantitative RT-PCR.

\section{Comparison of Real-Time RT-PCR and DNA Array Results}

Glyceraldehyde-3-phosphate dehydrogenase (G3PDH) is an abundantly expressed housekeeping gene in most cells, but regulation of expression has been reported under some conditions (11). By DNA array hybridization, G3PDH transcript was detected at equal levels in subdones 20863 and 20861. Real-time RT-PCR also detected G3PDH transcript at the same level in both subdones (Fig. 2) (9). The fidelity of the real-time PCR assay is demonstrated by the lack of specific signals for the no$\mathrm{RT}$ and $\mathrm{H}_{2} \mathrm{O}$ controls (Fig. 2) and by the CV determined for each gene. The mean CV for genes with high hybridization intensity was $12 \%$ (range: 1-25\%), and for those with low hybridization intensity, 18\% (range: 18-28\%).

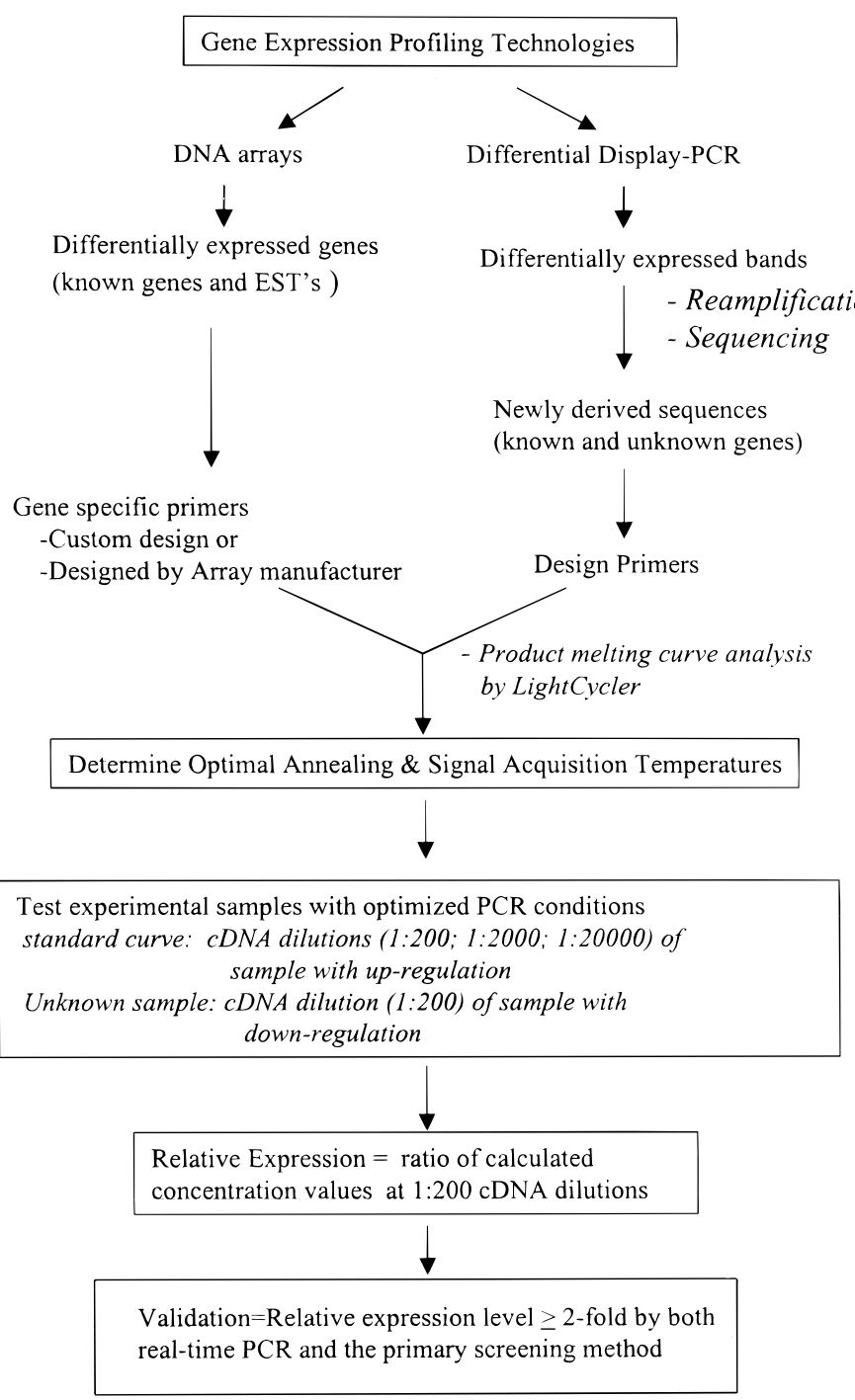

FIG. 1. Schematic diagram illustrating the sequence of events in using real-time RT-PCR for validation of genes identified as differentially expressed by DNA arrays and DD-PCR technologies. 
The relative change in expression for several genes as determined by CDNA array and real-time PCR are presented in Table 2, and an example of the amplification plot of a differentially expressed gene (vimentin) is given in Fig. 3. Real-time PCR confirmed the majority of CDNA array results (88\%) when the hybridization intensity was high (15 of 17 genes) or when the relative difference in expression between the subclones was greater than fourfold ( 5 of 5 genes). Genes detected as expressed in only one sample by array result were all of Iow intensity and only 1 of 4 genes was confirmed. Overall, real-time PCR confirmed CDNA array results for 17 of 24 genes (71\%) tested. Differences werealso seen in the magnitude of expression differences for genes concordant between CDNA array and real-timePCR. For example, among the 14 differentially expressed genes confirmed by real-time PCR, 10 genes showed expression differences greater than that determined by CDNA array.

Validation of DD-PCR Results

\section{Selection of DD-PCR Bands and Gene-Specific Primers}

The main difference in approach between DNA arrays and DD-PCR is that there is no sequence information associated with the DD-PCR bands. Therefore, the first step in validation of results requires excision of the band of interest from the DD-PCR gel and sequencing of the extracted DNA. Selected bands were excised and reamplified following the fluorescence DDPCR manual (Beckman and Coulter, Inc., F oster City, CA) except that Expand PCR K it (Roche Molecular Biochemicals) was used. The Expand PCR Kit was used in place of the recommended AmpliTaq DNA polymerase (PE Applied Biosystems) to increase the size of DDPCR fragments that could be reamplified from the excised HR-1000 gel matrix (Beckman and Coulter, Inc.). Reamplified products containing an intense band of the correct size on agarose gel (1.2\%) were sequenced following the instructions for theBigdye Terminator Cycle Sequencing Ready Reaction Kit (PE Applied Biosystems) and ABI 377 Sequencer (PE Applied Biosystems). Only sequences with $<10 \%$ ambiguous bases were used for validation. Bands containing mixtures of sequences are not suitable for validation by this approach until the predominant sequence has been identified by singlestrand conformational polymorphism or by sequencing of multiple clones. Once the sequence has been determined, the primers could be designed using the principles outlined in the section above (array validation).

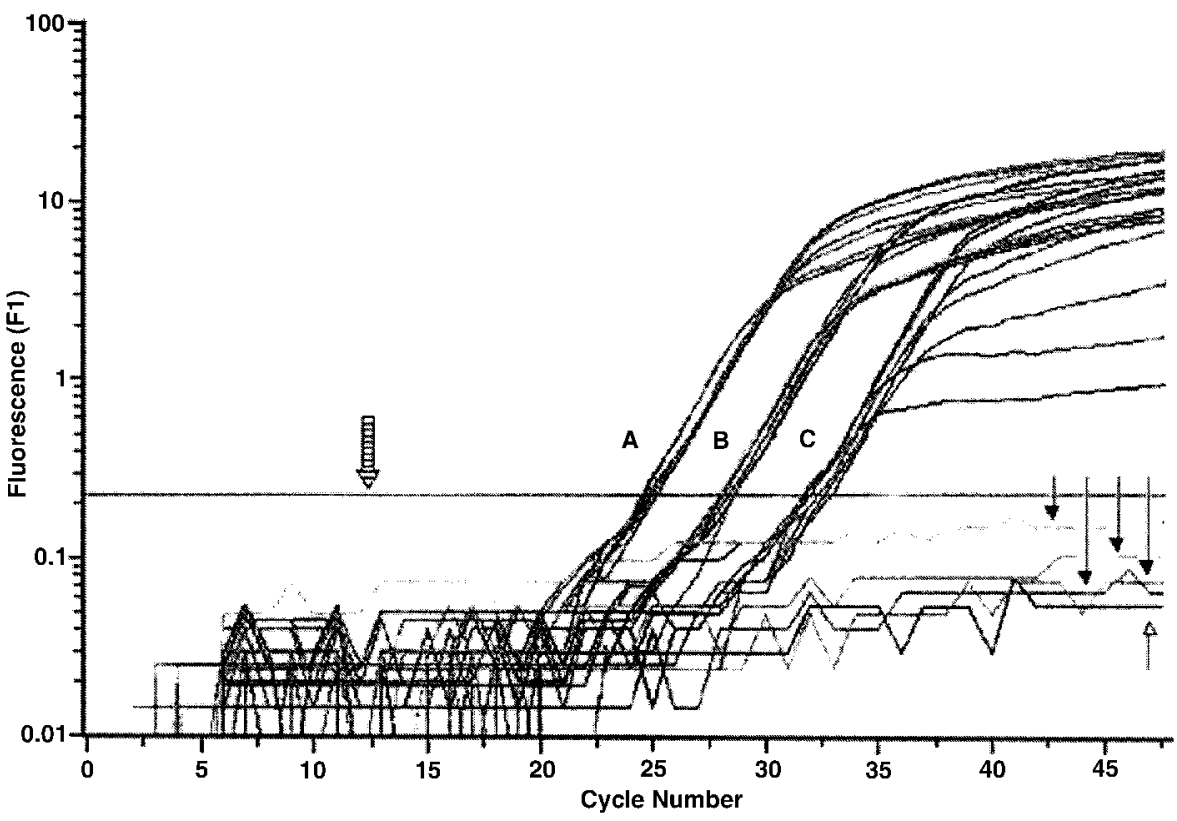

FIG. 2. Amplification plot (fluorescence vs cycle number) of G3PDH transcript in subclones 20863 and 20861 by real-time PCR assay based on SYBR Green I dye detection. Both subclones were evaluated for relative levels of G3PDH transcript using 1:200, 1:2000, and 1:20,000 dilutions of CDNA which are indicated as A, B, and C, respectively, in the amplification plot. There were four reactions per dilution per sample. At each dilution, all reactions overlapped in the log-linear phase indicating identical levels of G3PDH transcript in both samples. Closed arrowheads indicate no-RT controls with both subclones. Open arrowhead shows PCR with no template. Arrowhead with strips indicates the position of the noise band. All data points below the noise band were excluded from quantification. Annealing and signal acquisition temperatures for G3PDH are given in Table 2. Reprinted from M. S. Rajeevan, S. D. Vernon, N. Taysavang and E. R. Unger, J . Mol. Diagn. (2001) 3(1), 26-31, by permission from American Society for I nvestigative Pathol ogy and the Association for Molecular Pathol ogy. 


\section{Comparison of Real-Time RT-PCR and DD-PCR Results}

As an example, an optimized fluorescence-based differential display PCR (fluoro-DD-PCR) system (Beckman Coulter, Inc.) was used to identify genes differentially expressed between nondifferentiating monolayers and differentiating raft cultures of subclone 20861. Bands reproduced with equal intensity between the duplicate lanes of a sample were used for analysis. Bands were grouped as representing unique, 2- to 4fold, 5- to 10-fold, and >10-fold differences in gene expression based on visual assessment of relative band intensities. Bands representing upregulation, in either monolayer or raft, were also grouped as weak, moderate, and strong based on absolute intensity (Table 3).

The amplification plot (Fig. 4A) generated with primers designed from Band 1 sequence shows complete overlap in the log-linear phase at each cDNA dilution, suggesting that Band 1 is expressed at equal levels in both monolayers and rafts. The results for Band 1 obtained by real-time PCR and DD-PCR are concordant. The sharp and fully overlapping melting peaks at all CDNA dilutions (F ig. 4B) indicate that the primers designed from Band 1 sequence are specific for the quantification of the newly derived sequences. Realtime PCR was done to validate the expression pattern of a total of 13 DD-PCR bands. The mean CV for bands with low to moderate signal strength was $10.4 \%$ (range: 3-28.5\%), and for those bands with strong signal strength in the DD-PCR gel, 18\% (range: 0.8-30\%). Real-time PCR confirmed the DD-PCR expression pattern for all but 1 of 13 bands (92\%) representing known genes and ESTs, and various levels of relative and absolute band intensities.

\section{TABLE 2}

Validation of Array-Based Gene Expression Profile by Real-Time PCR

\begin{tabular}{|c|c|c|c|c|}
\hline \multirow[b]{2}{*}{ Gene name ${ }^{a}$ (Accession No.) } & \multirow[b]{2}{*}{$\begin{array}{l}\text { Annealing; acquisition } \\
\text { temperature }\left({ }^{\circ} \mathrm{C}\right)\end{array}$} & \multicolumn{2}{|c|}{ Relative expression ${ }^{b}$} & \multirow[b]{2}{*}{$\begin{array}{l}\text { Validation } \\
\text { (yes/no) }\end{array}$} \\
\hline & & $\begin{array}{l}\text { DNA } \\
\text { array }\end{array}$ & $\begin{array}{l}\text { Real-time } \\
\text { PCR }\end{array}$ & \\
\hline \multicolumn{5}{|l|}{ Intensity $>30^{c}$} \\
\hline Fibronectin (X02761) & $58 ; 85$ & 8.5 & 20.0 & Y \\
\hline Stromelysin 2 (X07820) & $55 ; 81$ & 5.2 & 8.4 & $\mathrm{Y}$ \\
\hline Bullous pemphigoid antigen (M63618) & $58 ; 83$ & 4.7 & 4.0 & $\mathrm{Y}$ \\
\hline BIGH3 (M77349) & $58 ; 83$ & 4.4 & 6.8 & Y \\
\hline Plasminogen activator inhibitor (X04229) & $60 ; 86$ & 3.9 & 5.1 & $\mathrm{Y}$ \\
\hline Collagenase 1 (X05231) & $58 ; 83$ & 3.0 & 4.7 & $\mathrm{Y}$ \\
\hline Interleukin (IL)-1 $\beta$ (K02770) & $55 ; 86$ & 2.8 & 4.6 & Y \\
\hline Integrin $\alpha 6$ (X59512) & $62 ; 80$ & 2.4 & 3.2 & Y \\
\hline IFN- $\gamma$ antagonist cytokine (A25270) & $62 ; 85$ & 2.4 & 0.9 & $\mathrm{~N}$ \\
\hline Zyxin + zyxin 2 (X94991) & $59 ; 90$ & 2.3 & 2.0 & Y \\
\hline$\beta$-Catenin (X87838) & $60 ; 87$ & 2.1 & 1.0 & $\mathrm{~N}$ \\
\hline Vimentin (X56134) & $58 ; 83$ & 2.0 & 23.2 & Y \\
\hline Leukocyte interferon-inducible peptide ${ }^{d}$ (X66357) & $58 ; 81$ & 2.2 & 7.3 & Y \\
\hline Cytokeratin 19d (X00503) & $58 ; 83$ & 2.5 & 4.1 & $\mathrm{Y}$ \\
\hline Cyclin (PCNA, J 04718) & $60 ; 88$ & 1.1 & 1.0 & $\mathrm{Y}$ \\
\hline CDK-interacting protein 1 (U09579) & $58 ; 86$ & 1.0 & 1.0 & Y \\
\hline G3PDH (X01677) & $58 ; 86$ & 1.0 & 1.0 & Y \\
\hline \multicolumn{5}{|l|}{ Intensity $<30$} \\
\hline Desmoplakin I (M77830) & $62 ; 87$ & 4.2 & 2.7 & Y \\
\hline Thrombospondin 1 precursor (X14787) & $60 ; 88$ & 3.5 & 0.8 & $\mathrm{~N}$ \\
\hline Mitogen-inducible gene 5 (Z30183) & $60 ; 88$ & 2.7 & 1.4 & $\mathrm{~N}$ \\
\hline Tenacin- C (X78565) & $62 ; 86$ & Unique & Unique & Y \\
\hline Disheveled homolog (U46461) & $65 ; 86$ & Unique & 1.0 & $\mathrm{~N}$ \\
\hline Bone morphogenetic protein (M22488) & $67 ; 89$ & Unique & 0.8 & $\mathrm{~N}$ \\
\hline Cell division protein kinase C (X66357) & $62 ; 88$ & Unique & 0.9 & $\mathrm{~N}$ \\
\hline
\end{tabular}

a Primer sequences for these genes on DNA arrays are available from Clontech (Palo Alto, CA).

${ }^{b}$ Relative expression is calculated as ratio (R) of expression levels in subclone 20863/subclone 20861 or the reciprocal of this ratio (1/R) to indicate genes up- or downregulated, respectively, in subclone 20863. A gene is considered differentially expressed in this article if its relative expression is twofold or greater or unique.

c Intensity groups are based on the normalized array hybridization intensity values of subclone 20863.

d Genes downregulated in subclone 20863. All other genes upregulated/expressed identically or uniquely in subclone 20863 by DNA arrays.

Source Reprinted from M. S. Rajeevan, S. D. Vernon, N. Taysavang and E.R. Unger, J . Mol. Diagn. (2001) 3(1), 26-31, by permission from American Society for Investigative Pathology and the Association for Molecular Pathology. 


\section{TABLE 3}

Validation of DD-PCR Results by Real-Time Quantitative PCR

\begin{tabular}{|c|c|c|c|c|c|}
\hline \multirow[b]{2}{*}{ Band No. } & \multirow[b]{2}{*}{$\begin{array}{c}\text { Band } \\
\text { intensity }\end{array}$} & \multirow[b]{2}{*}{$\begin{array}{l}\text { Band size } \\
\text { (bp) }\end{array}$} & \multicolumn{2}{|c|}{ Relative expression } & \multirow[b]{2}{*}{$\begin{array}{l}\text { Validation } \\
\text { (yes/no) }^{\text {b }}\end{array}$} \\
\hline & & & DD-PCR & $\begin{array}{c}\text { Real- } \\
\text { time PCR }\end{array}$ & \\
\hline \multicolumn{6}{|c|}{ Upregulated bands in monolayers } \\
\hline 11 & Weak & 1000 & $2-4$ & 5.7 & Yes \\
\hline 47 & Weak & 1035 & $2-4$ & 3.3 & Yes \\
\hline 18 & Moderate & 390 & $2-4$ & 2.2 & Yes \\
\hline 17 & Strong & 475 & $5-10$ & 3.9 & Yes \\
\hline 72 & Strong & 510 & $>10$ & 4.7 & Yes \\
\hline 136 & Strong & 510 & $>10$ & 3.5 & Yes \\
\hline \multicolumn{6}{|c|}{ Upregulated bands in rafts } \\
\hline $98^{\mathrm{c}}$ & Strong & 1150 & Unique & 5.7 & Yes \\
\hline $36^{c}$ & Strong & 1150 & $5-10$ & 17 & Yes \\
\hline 15 & Strong & 610 & $5-10$ & 0.4 & No \\
\hline $66^{c}$ & Strong & 910 & $5-10$ & 2.3 & Yes \\
\hline $79^{c}$ & Strong & 455 & $5-10$ & 3.2 & Yes \\
\hline \multicolumn{6}{|c|}{ Bands with equal intensity } \\
\hline 1 & Strong & 640 & 1.0 & 1.2 & Yes \\
\hline 2 & Moderate & 425 & 1.0 & 1.1 & Yes \\
\hline
\end{tabular}

${ }^{a}$ Band intensity refers to the signal strength of higher-intensity band in either monolayer or raft.

${ }^{b} \mathrm{~A}$ differentially expressed band by DD-PCR is considered validated if the relative expression ratio determined by real-time PCR is $\geq 2$.

' Sequences identified as novel or homologs toESTs in the database. All other bands were identified as known genes.

\section{TECHNICAL TIPS}

1. RNA quality is the single most important variable in all gene expression analyses. Commercial RNA extraction kits may give unpredictable results in terms of yielding pure and undegraded RNA compatible with the range of enzymatic reactions and detection systems used in gene expression analyses. RNA integrity should be preserved during prolonged storage since results from genomewide expression profiling methodologies may become available for validation studies only several weeks or months after RNA extraction. Total RNA was treated with DNase I (0.4 units/ $\mu$ g RNA) according to the instructions of the MessageClean kit (GenHunter Corp., Nashville, TN). RNA was quantified by UV spectrophotometry and was checked for absence of degradation by denaturing formaldehyde agarose gel electrophoresis (12).

2. An alternate protocol for DNase I treatment (13) may be used if RNA is limited $(<10 \mu \mathrm{g})$. The alternate protocol treats RNA with DNase I in the RT reaction buffer prior to the addition of reverse transcriptase enzyme, and avoids phenol-chloroform extraction which often results in loss of starting RNA. We tested the efficiency of this DN ase I treatment for limited amounts of RNA under real-time RT-PCR conditions described here, and found it to be satisfactory.

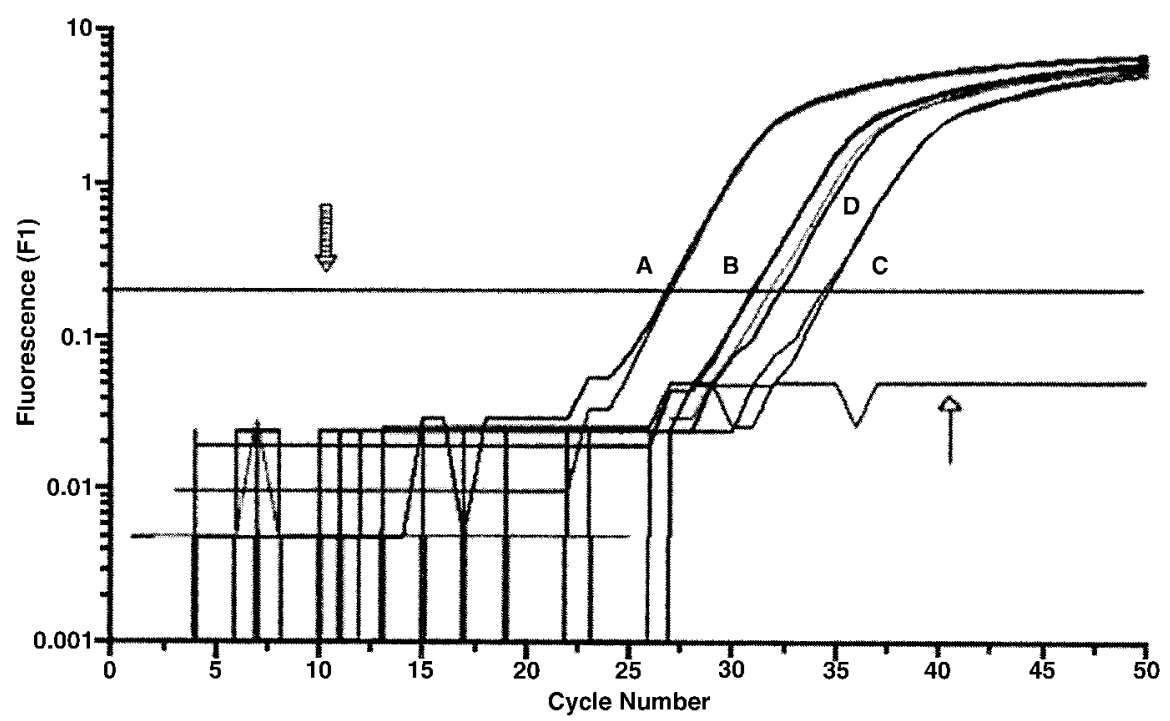

FIG. 3. Amplification plot of a gene (vimentin) identified as differentially expressed between two subclones of a cervical epithelial cell line by DNA array technology. CDNA dilutions (1:200, 1:2000, 1:20,000 indicated as A, B, C, respectively) of subclone 20863 with high hybridization intensity for vimentin were used to generate the standard curve. cDNA dilution (1:200, marked as D) of subclone 20861 with low hybridization intensity was entered as unknown. All dilutions were tested in duplicate. The log-linear phase of 1:200 dilution of subclone 20861 is seen below the log-linear phase of 1:2000 cDNA dilution of subclone 20863. The calculated concentration values by LightCycler at 1:200 cDNA dilutions showed a 23-fold higher level of vimentin transcript in subclone 20863, a result validating differential expression of vimentin by DNA arrays. Arrowhead with strips indicates the noise band set to eliminate background signal. The signal from negative control (open arrow) was well below the noise band. 

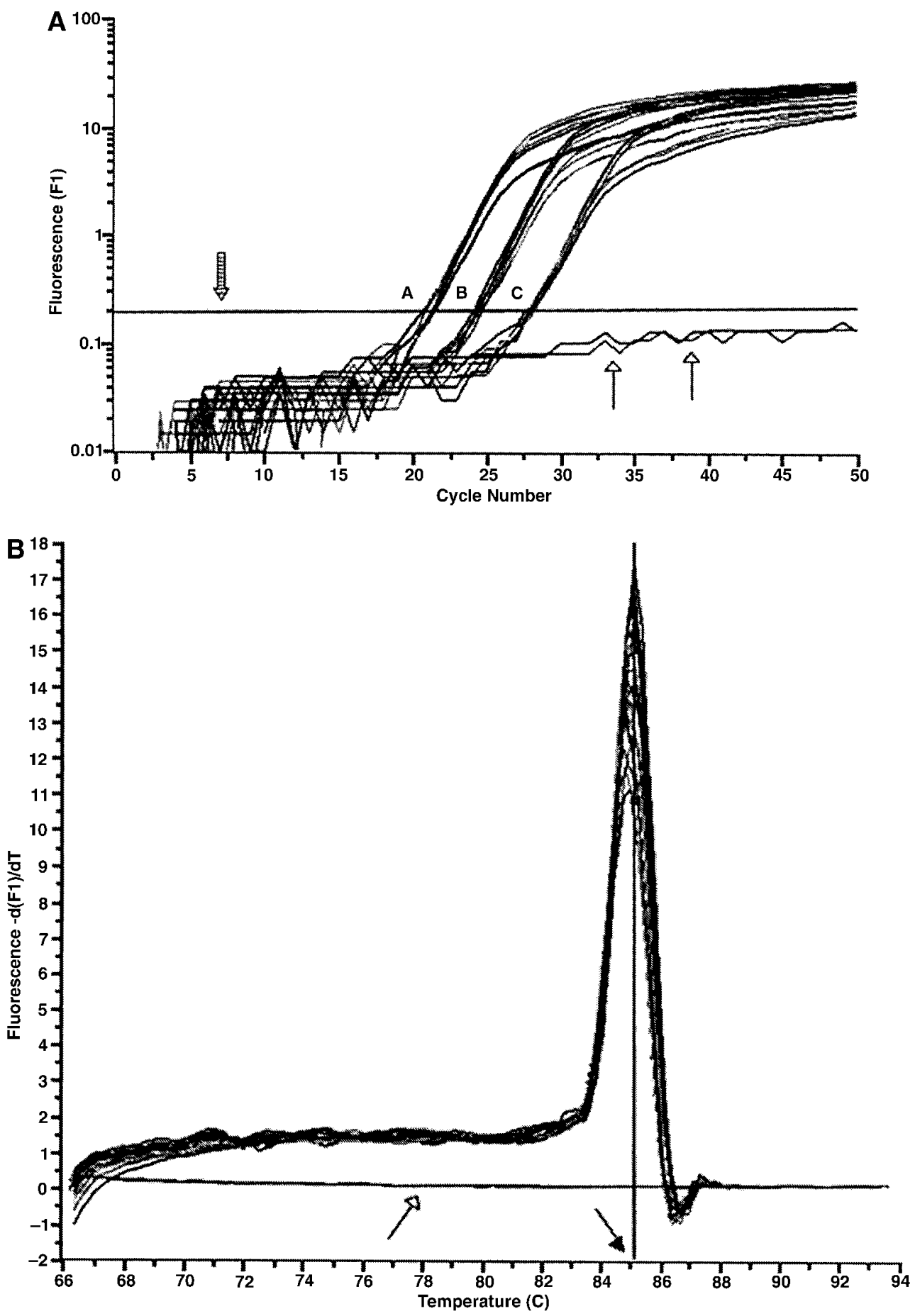

FIG. 4. (A) Cycle number versus fluorescence plot generated with primers designed from DD-PCR Band 1 sequence. Band 1 was present in the DD-PCR gel with equal intensity in both rafts and monolayers of subclone 20861. The three dilutions $(1: 200,1: 2000,1: 20,000)$ of CDNA from both monolayer and raft are indicated as A, B, and C, respectively, in the amplification plot. Each dilution was tested in quadruplicate. Note the complete overlapping in the log-linear phase at each dilution, indicating equal levels of transcript for Band 1 in monolayer and rafts. Open arrows indicate fluorescence signal below the noise band (arrowhead with stripes) for water and no-RT controls. Signal below the noise band was not considered for quantitative analysis. (B) Temperature versus fluorescence $[-\mathrm{d}(\mathrm{F} 1) / \mathrm{dT}]$ for Band 1 sequence. All reactions with CDNA template showed one sharp and fully overlapping melting peak indicating the specificity of primers designed from partial gene sequences. Open arrow indicates the melting curve with no peaks for water and no-RT controls. Closed arrow indicates the melting temperature $\left(T_{m}\right)$ of specific product in these reactions. 
3. If experimental sample RNA is limited, RNA from an easily available source of the same species/genotype (human RNA for human CDNA array or mouse RNA for mousecDNA array) can beused for the determination of optimal annealing and signal acquisition temperatures. However, RNA from these additional sources should be extracted and purified in the same manner as experimental samples since $T_{m}$ values can be influenced by variations in theamounts of residual salts and other impurities.

4. Certain primer pairs may result in multiple peaks in the melting curve analysis even after several attempts with different primer annealing temperatures and hold times. This may indicate nonspecificity of primers or complex transcriptional regulation such as alternate splicing events or detection of novel gene family members. Products may be recovered from glass capillaries in such cases for gel electrophoresis and sequencing for product verification.

\section{CONCLUDING REMARKS}

Hot-start PCR and fluorescence signal acquisition at temperatures just below the $T_{m}$ of specific product allowed SYBR Green I dye-based real-timePCR to besensitive and specific (10). The technique described here yielded results with an average $C V$ of $15 \%$ for genes with high and low hybridization intensities based on CDNA array hybridization or for DD-PCR bands with low to strong signal strength. This average CV is well below the reported average of $25-35 \%$ for gene quantification with real-time PCR. Most genes selected either by CDNA array or DD-PCR could be confirmed by real-time PCR by using dilutions of CDNA as low as 1:200 to 1:20,000 from a standard $20-\mu$ l RT reaction with $1 \mu \mathrm{g}$ total RNA. Since real-time PCR assay can be done with extremely small amounts of CDNA, nearly 100-1000 genes identified by high-throughput differential screening procedures can bevalidated with $1 \mu \mathrm{g}$ of total RNA. Validation with Northern blot or RNase protection assay, on the other hand, requires at least $5 \mu \mathrm{g}$ of total RNA per assay, approximately 5000 times more RNA than for the realtime PCR assay reported here.

Real-time PCR validated DD-PCR bands that represented various levels of absolute and rel ative band intensity, suggesting that the likelihood of validating a DDPCR band is not dependent on band intensity differences. On the other hand, both the hybridization intensity and the relative level of gene expression influenced the likelihood that CDNA array results were validated. The level of expression differences measured by real-time PCR for many genes was quite different when compared with the results of respective primary screening method. This disagreement may be due to the lack of specificity in the primers designed to discriminate gene family members at the level of primary screening by DNA arrays or DDPCR. Until DNA arrays are optimized for measurement of sequence-specific transcripts, it is possible for cDNA array results to be masked by cross-hybridization of related gene family members. Similarly, designing specific primers for validation of DD-PCR bands could belimited by the lack of information on sequence relatedness to gene families and regulation of novel transcripts. The strength of real-timePCR assay as a secondary validation procedure lies in its potential to quantify relative change in expression of large numbers of known and novel genes with limited RNA in a rapid and precise manner.

\section{ACKNOWLEDGMENTS}

We acknowledge the expert technical assistance of Daisy Lee, I rina Dimulescue, Naovarath Taysavang, and Deon Brown. Use of trade names and commercial sources does not imply endorsement by the Centers for Disease Control and Prevention or the U.S. Department of Health and Human Services. D.G.R. was supported by the U.S. Department of Energy and CDC Interagency Agreement administered by the Research Participation Program of the Oak Ridge Institute for Science and Education.

\section{REFERENCES}

1. Der, S. D., Zhou, A., Williams, B. R. G., and Silverman, R. H. (1998) Proc. Natl. Acad. Sci. USA 95, 15623- 15628.

2. Eisen, M., and Brown, P. O. (1999) Methods Enzymol. 303, 179205.

3. Winzeler, E. A., Schena, M., and Davis, R. W. (1999) Methods Enzymol. 306, 3- 19.

4. Schuchhardt, J., Beule, D., Malik, A., Wolski, E., Lehrach, H., and Herzel, H. (2000) Nucleic Acids Res. 28(10), E47.

5. Poirier, G. M. C., and Erlander, M. G. (1998) Methods 16, 444452.

6. Siebert, P. D. (1997) in Methods in Molecular Medicine, Vol 13: Molecular Diagnosis of I nfectious Diseases (Reischi, U., Ed). Humana Press, Clifton, NJ .

7. Higuchi, R., Fockler, C., Dollinger, G., and Watson, R. (1993) Bio/ Technology 11, 1026-1030.

8. Wittwer, C. T., Herrmann, M. G., Moss, A. A., and Rasmussen, R. P. (1997) BioTechniques 22, 130-138.

9. Rajeevan, M. S., Vernon, S. D., Taysavang, N., and Unger, E. R. (2001) J. Mol. Diagn. 3(1), 26-31.

10. Morrison, T. B., Weis, J . J ., and Wittwer, C. T. (1998) BioTechniques 24, 954-962.

11. Schmittgen, T. D., and Zakrajsek, B. A. (2000) J . Biochem. Biophys. Methods 46(12), 69-81.

12. Sambrook, J ., Fritsch, E. F., and Maniatis, T. (1989) in Molecular Cloning: A Laboratory Manual, Cold Spring Harbor Laboratory Press, Cold Spring Harbor, NY.

13. Huang, Z., F asco, M. J ., and Kaminsky, L. S. (1996) BioTechniques 20, 1012-1020. 